\title{
Management and Incidence of EBV Infection in Children after Liver Transplantation Treated With Tacrolimus
}

\author{
Borgnia D*, Dip M, Arrieta W, Viale D, Halac E, Aredes D, Cervio G, \\ Martinito R, Sarkis C, Bosaleh A, Lencina A, Nuñez A, and \\ Imventarza 0
}

Hospital de Pediatria Dr. Juan P. Garrahan, Argentina

\section{Research Article \\ Volume 1 Issue 1}

Received Date: August 18, 2017

Published Date: October 12, 2017

DOI: $10.23880 / \mathrm{ijtps}-16000103$

*Corresponding author: Maria Daniela Borgnia, Hospital de Pediatría Dr. Juan P. Garrahan, Combate de los Pozos 1881, Argentina, Tel: 0111521884012; E-mail: md_borgnia@yahoo.com.ar

\section{Abstract}

Posttransplant lymphoproliferative disorder (PTLD) causes significant morbidity and mortality in pediatric liver transplantation recipients.

Objective: To describe the management and outcome of patient with EBV infection diagnosed using quantitative competitive polymerase chain reaction.

Materials and Methods: Retrospective descriptive study of 80 pediatric liver transplantations performed between 2009 and 2012 at the Hospital de Pediatría Prof. "Dr. Juan P. Garrahan" in Argentina. Median time of follow-up was 21.5 months (r: 3.6 to 40 ).

Results: $38.7 \%$ (31/80) of patients developed EBV infection. The rate of acute rejection in patients with EBV infection was $64.5 \%$ (20/31). Four patients (4.3\%) developed PTLD and were treated with rituximab. In this series, overall patient survival was $96 \%$. One death was related to PTLD (1/4).

Conclusion: Viral load monitoring and preventive immunomodulation are safe and effective management strategy patients with EBV infection. Children under two years of age, EBV-naive recipients, and those who develop more rejection episodes are at risk of PTLD.

Keywords: Epstein-Barr virus (EBV); Liver transplantation; Pediatric; Post-transplant lymphoproliferative disorder (PTLD)

Abbreviations: AR: Acute Rejection; CR: Chronic Rejection; CMV: Cytomegalovirus; DNA: Deoxyribonucleic acid; EBV: Epstein-Barr virus; EBV-I: Epstein-Barr virus infection; EBV-PTLD: Epstein-Barr virus associated posttransplant lymphoproliferative disease; EBER-ISH:
Epstein-Barr encoding region in situ hybridization; GR: Graft Rejection; LT: Liver Transplantation; SEBV: Symptomatic Epstein-Barr Virus; IS: Immunosuppression; PCR: Polymerase Chain Reaction; PTLD, Posttransplant Lymphoproliferative Disease; TAC: Tacrolimus. 


\section{International Journal of Transplantation \& Plastic Surgery}

\section{Introduction}

Epstein-Barr virus (EBV) is a $\gamma$ - herpesvirus that infects more than $90 \%$ of the world's population. In healthy subjects, primary EBV infection is usually asymptomatic in childhood or presents as a non-specific viral illness (infectious mononucleosis) during adolescence or adulthood [1]. Although it is often present as infectious mononucleosis in adolescence, $30-45 \%$ this is usually still the minority of seroconverters.

Primary lytic EBV infection occurs in the oropharynx and triggers a robust humoral and cellular immune response. After clearance of the primary infection, EBV persists in infected B-lymphocytes, establishing latent infection [2,3]. Pharmacologic immunosuppression (IS) after transplantation leads to decreased frequency and functional impairment of EBV-specific T cells. Children undergoing liver transplantation (LT) frequently develop a primary EBV infection or a reactivation, which places them at a marked risk of developing EBV disease, including posttransplant lymphoproliferative disease (PTLD). PTLD occurs in immunosuppressed LT recipients due to uncontrolled lymphoproliferation, which is controlled in immunocompetent individuals. PTLD is the commonest form of post-transplant malignancy in pediatric transplant recipients and is an important cause of morbidity and mortality [4-6].

In the majority of cases PTLD is associated with EBV with a wide spectrum of presentation ranging from polyclonal lymphoproliferation to lymphoma [7]. EBVassociated PTLD (EBV-PTLD) most commonly presents in the first two years post-transplantation while EBVnegative PTLD occurs later [8]. Risk factors for developing PTLD reported in the literature include: EBV-seronegative recipient, age of the recipient, degree of IS, immunosuppressive regimen, and first year posttransplantation [5,9-11].

The overall prevalence of EBV- PTLD following pediatric LT ranges from $6 \%$ to $20 \%$ and the mortality rate from $12 \%$ to $60 \%[5,6]$.

As a serious complication of solid organ transplantation, prompt diagnosis and intervention is necessary.

The aim of our study was describe the management and outcome of patients with Epstein-Barr virus infection (EBV-I), diagnosed using polymerase chain reaction
(PCR), with or without progression to PTLD treated with tacrolimus (TAC) as primary IS.

\section{Material and Methods}

We conducted a retrospective, descriptive study of 80 pediatric LT recipients under TAC primary IS seen between November 2009 and December 2012 to select patients with diagnosis of EBV by PCR with or without progression to symptomatic Epstein Barr virus (SEBV) or PTLD after transplantation. Retransplanted patients $(n=10)$ and those who died within one month after transplantation $(\mathrm{n}=1)$, were excluded $(\mathrm{n}=11)$ (Figure 1). Mean follow-up time was 21.5 months (3.6 - $40.1 \mathrm{~m}$ ).

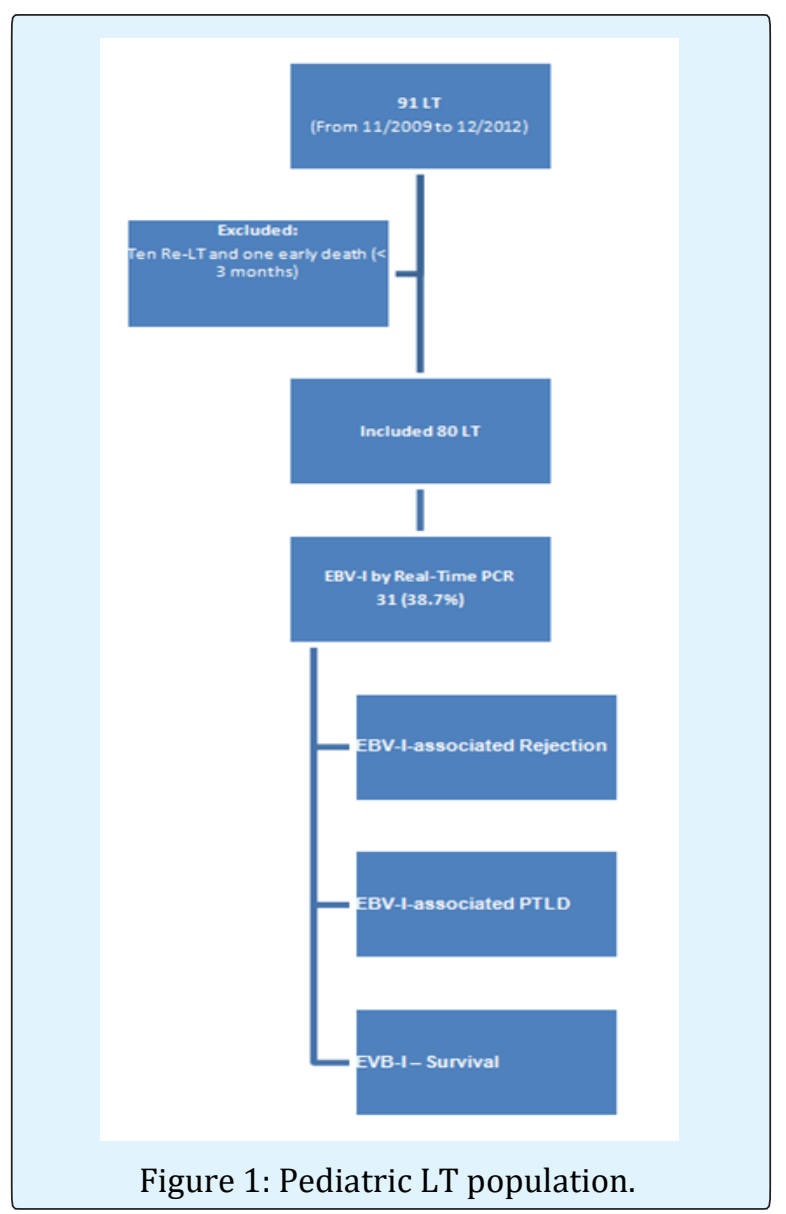

Clinical variables, including sex and age at transplant, indication for transplant, transplant type (deceased cadaveric vs. living-related donor), recipient EBV serostatus at time of transplant, development of Citomegalovirus (CMV) viremia by PCR, time from transplant to EBV-I, serum TAC level at time of primary infection and monthly averaged, number and degree of 


\section{International Journal of Transplantation \& Plastic Surgery}

rejection episodes, PTLD diagnosis, and outcomes were recorded. All PTLDs and rejections were diagnosed histologically by institutional pathologists. PTLD was graded according to the Harris el al. classification [12]. Rejection was graded using the Rejection Activity Index [13].

\section{EBV Serostatus and Viral-Load Monitoring}

EBV serostatus at the time of transplantation was determined by IgG positivity. All children under the age of 12 months were presumed to be EBV naive because positive titers could still be of maternal origin from transplacental transfer. Serology has no value for the diagnosis of active disease.

EBV-I was defined as development of a positive viral load by PCR without associated symptoms or signs. Chronic high EBV load carriers were defined as having loads of $\geq 16,000$ genome copies $/ \mathrm{mL}$ of whole blood in at least $50 \%$ of load measurements over a minimum 6month period of monitoring [14].

EBV PCR was checked every week in the first 2-3 months after liver transplantation, then monthly for one year, and quarterly thereafter. Changes to $0.5 \mathrm{log}$ variation between samples were considered clinically significant.

EBV disease was defined as the development of a positive viral load with either histological evidence of an EBV-I (as determined by the local pathologist) or symptoms associated with an EBV-I (fever, leukopenia, atypical lymphocytosis, exudative tonsillitis and/or adenopathy, or hepatitis). PTLD was defined locally on the basis of the minimum requirement of a tissue biopsy sample considered diagnostic of PTLD by the local pathologist according to the published classification scheme by Harris. Late PTLD was defined as the presentation of the disease 12 months after liver transplantation.

\section{EBV DNA Extraction and Real-Time PCR for Viral DNA}

Automated extraction systems were used for DNA extraction from whole peripheral blood using a QIAamp DNA mini-kit (Qiagen, Tokyo, Japan), as described elsewhere. DNA was extracted from $200 \mu \mathrm{l}$ of whole blood with a spin column (QIAamp DNA mini-kit, Qiagen, Tokyo, Japan), and eluted into $100 \mu$ l of buffer AE (Qiagen). Eluates were stored at $-20^{\circ} \mathrm{C}$ until needed. Each patient with previous negative or unknown loads was tested for the presence of EBV DNA using an in-house qualitative real-time PCR assay. All positive samples were evaluated for EBV DNA loads using EBV Q- PCR Alert Kit (Nanogen ELITechGroup) according to the manufacturer's recommendations. When the patient had a previous positive result, EBV viral load was measured directly. The region selected for the qualitative real time EBV PCR assay was the BALF 5 gene (viral DNA polimerase). The gene region that codifies the EBNA-1 protein of EBV is the target in the EBV Q-PCR Alert Kit. Both trials use $\beta$-globin as internal control [15]. The PCR product was detected with the 7500 real-time PCR System (Applied Biosystems). Viral loads are expressed as DNA copies per $\mathrm{ml}$ of blood and its logarithm. Changes to $0.5 \mathrm{log}$ variation between samples were considered clinically significant.

\section{Induction and Maintenance Immunosuppression}

All patients underwent induction with basiliximab, an anti-IL-2 receptor antibody, $(1 \mathrm{mg} / \mathrm{kg}$ intravenous for one dose intra-operatively), with delayed initiation of TAC on post-operative day $2(0.05 \mathrm{mg} / \mathrm{kg}$ oral twice daily with dose adjustment to reach a therapeutic range of around 7$10 \mathrm{ng} / \mathrm{mL}$ ). After one year, most patients with a stable graft function received maintenance IS with TAC monotherapy. Prophylaxis for CMV with ganciclovir was administered intravenously ( $5 \mathrm{mg} / \mathrm{kg} / \mathrm{dose}$ ) for the first 2 weeks often in the range of 3 to 6 months after LT for all seronegative patients who received seropositive grafts and infants under 12 months $[16,17]$. Acute rejection (AR) were treated with 3 steroid bolus therapy at $5 \mathrm{mg} / \mathrm{kg}$ [18].

\section{Management Protocol for Patients with EBV-I and SEBV or PTLD}

In asymptomatic patients with more than twice EBV load $>4000$ copies $/ \mathrm{ml}$ (3.6 log) increasing and liver test normal we reduced TAC level and they were closely followed for signs of SEBV or PTLD and AR as well. Furthermore, patients who were suspected of developing PTLD received full-body computed tomography scans to assess for any radiographic signs. In patients with a diagnosis of SEBV or PTLD who failed to respond adequately to reduction of immunosuppressive drugs we used rituximab.

\section{Statistical Analysis}

Continuous data are presented as medians and ranges and categorical data as counts (percentage of total). Univariate analysis of group characteristics was 


\section{International Journal of Transplantation \& Plastic Surgery}

performed using the Fisher's exact test. Group medians were compared using the equality of medians test. Kaplan-Meier probability estimates were used to predict patient and graft survival after liver transplantation. All statistical analyses were conducted at an alpha $<0.05$ employing two-sided tests using SPSS software.

\section{Results}

Thirty-one patients out of 80 primary LT developed EBV-I $(38,7 \%)$ at a median time of 81 days (r: 5-872) after LT. Demographic characteristics of the patients are listed in Table 1. The median age at LT was 1 year (r: 0.4-17). Nineteen patients $(61.3 \%)$ were considered to be at high risk for developing EBV-I and seven (22.6\%) for developing CMV infection.

The median EBV DNA loads at EBV-I diagnosis was 3.3 $\log$ ( $r: 1.56-6.08$ ) and the peak max value reached was $4.8 \log$ (r: 3.8-6.6). Of the 31 children, seventeen (54.8\%) met the criteria for chronic high EBV load carriers. Twenty-four children (77.4 \%) had evidence of CMV infection at a median of 14 days (r: 0-236) after LT and were treated with ganciclovir and none of them progressed to CMV disease (Table 1). Of all CMV-related infections, seven were reactivations and 17 were primary infections.

\begin{tabular}{|c|c|}
\hline \multicolumn{2}{|c|}{ All Patients } \\
\hline & n: 31 \\
\hline Time from transplant to EBV-I (days)* & $81(\mathrm{r}: 5-872)$ \\
\hline Age at Transplant (years) & $1(\mathrm{r}: 0.4-17)^{*}$ \\
\hline Female & $71 \%(n=22)$ \\
\hline \multicolumn{2}{|c|}{ Primary Diagnosis } \\
\hline Biliary Atresia & $58 \%(n=18)$ \\
\hline Acute Liver Failure & $16 \%(n=5)$ \\
\hline Tumors & $9,6 \%(n=3)$ \\
\hline Others & $13 \%(n=4)$ \\
\hline \multicolumn{2}{|l|}{ Type of LT } \\
\hline Deceased Donor (DD) & $64.5 \%(n=20)$ \\
\hline Living Donor (LD) & $35.5 \%(n=11)$ \\
\hline \multicolumn{2}{|c|}{ Serological High Risk Status $†$} \\
\hline EVB & $61.3 \%(n=19)$ \\
\hline CMV & $22.6 \%(n=7)$ \\
\hline CMV Infection & $77.4 \%(24 / 31)$ \\
\hline \multicolumn{2}{|c|}{ TAC Level (ng/mL) $€$} \\
\hline At EBV-I Diagnosis & 5.7 (r: 1-15) \\
\hline 1 Month before EBV-I & $5.3(\mathrm{r}: 1,2-14)$ \\
\hline Acute Rejection (AR) & $64.5 \%(n=20)$ \\
\hline \multicolumn{2}{|c|}{ EBV load $(\log 10)^{¥}$} \\
\hline At Diagnosis & 3.3 (r: $1.5-6.0)$ \\
\hline Peak value & 4.8 (r: 3.8-6.6) \\
\hline Chronic High EBV Load t & $54.8 \%(n=17)$ \\
\hline
\end{tabular}

* Time from transplant to the first positive load

† Donor +/Recipient- o R $\leq 12$ months of age

$€$ Level of tacrolimus expressed in $\mathrm{ng} / \mathrm{ml}$ at the first positive load and the median during the previous months at the infection

$¥$ Logarithm of the number of copies per ml blood at the first positive load and logarithm of the number of copies per ml blood at its highest value of viral load

Ł EBV viral loads of $\geq 16,000$ genome copies/mL of whole blood in at least $50 \%$ of load measurements over a minimum 6 month period of monitoring

Table 1: Baseline Characteristics of Patients with EVB-I. 


\section{International Journal of Transplantation \& Plastic Surgery}

\section{EBV-I associated rejection}

Twenty (64.5\%) of $31 \mathrm{EBV}-\mathrm{I}$ patients developed at least one episode of AR at a median time of 83 days (r: 12-582) after LT; in only five of them (25\%) AR occurred 6 months after LT. In 12 patients $(60 \%)$ the first episode of AR occurred before and in eight (40\%) after EBV-I. The median time from EBV-I to the first AR was 81 days (r: 3504). Ten (50\%) of 20 first graft rejection were characterized as moderate to severe and were treated. None of them was found to be a steroid-resistant rejection. Eight of the 20 patients (40\%) developed more than one AR (a mean of 1.6 per patient), occurring before the EBV-I in seven $(87,5 \%)$ of them. Only two $(10 \%)$ children progressed to chronic rejection (CR) after PTLD diagnosis. None of the patients that were rejection free progressed to PTLD or died (Table 2).

\begin{tabular}{|c|c|c|c|}
\hline & Rejection & No Rejection & p Value \\
\hline & n: 20 & n: 11 & Pvalue \\
\hline Time from transplant to EBV-I (days)* & $143 \pm 180$ & $234 \pm 283$ & 0.05 \\
\hline Age at Transplant (years) & $2.2 \pm 3.7$ & $2.0 \pm 2.7$ & 0.8 \\
\hline EBV Serological High Risk Status $\dagger$ & $60 \%(n=12)$ & $63 \%(n=7)$ & 0.8 \\
\hline CMV Infection & $80 \%(16)$ & $72 \%(8)$ & 0.6 \\
\hline \multicolumn{4}{|c|}{ TAC Level (ng/mL) $€$} \\
\hline At EBV-I Diagnosis & $6.5 \pm 3.6$ & $5.2 \pm 1.8$ & 0.06 \\
\hline 1 Month before EBV-I Diagnosis & $6.7 \pm 3.9$ & $5.2 \pm 1.8$ & 0.04 \\
\hline \multicolumn{4}{|c|}{ EBV load $(\log 10)^{¥}$} \\
\hline At EBV-I Diagnosis & $3.3 \pm 1.2$ & $3.7 \pm 1.2$ & 0.9 \\
\hline Peak value & $4.9 \pm 0.6$ & $4.9 \pm 0.6$ & 0.7 \\
\hline Chronic High EBV Load $^{\star}$ & $55 \%(\mathrm{n}=11)$ & $54 \%(n=6)$ & 0.9 \\
\hline PTLD & $20 \%(n=4)$ & $0 \%(n=0)$ & 0.1 \\
\hline Mortality & $10 \%(\mathrm{n}=2)$ & $0 \%(n=0)$ & 0.2 \\
\hline
\end{tabular}

NOTE: Values in bold are statistically significant.

* Time from transplant to the first positive load

† Donor +/Recipient- o R $\leq 12$ months of age

$€$ Level of tacrolimus expressed in $\mathrm{ng} / \mathrm{ml}$ at the first positive load and the median during the previous months at the infection

$¥$ Logarithm of the number of copies per ml blood at the first positive load and logarithm of the number of copies per ml blood at its highest value of viral load

€ EBV viral loads of $\geq 16,000$ genome copies/mL of whole blood in at least $50 \%$ of load measurements over a minimum 6 month period of monitoring.

Table 2: Univariate Analysis of risk factors for rejection.

\section{EBV-I-associated PTLD}

Four of 31 (12.9\%) EBV-I transplanted patients develop PTLD, accounting for $5 \%$ of all primary LT performed using TAC, at a median of 364 days (171-572) after LT and 213 days (148-352) after EBV-I. Two PTLD were late of presentation (at 527 and 563 days).

The median age at PTLD diagnosis was 12 months ( $\mathrm{r}$ : 10-18 months). In all cases the clinical manifestations consisted of lymphadenopathy and extranodal disease (3 hepatitis and 1 enteritis). Tissue was available for pathologic review in all cases and two were classified as so-called "early lesions" and two as polymorphous PTLD.
In three cases Epstein-Barr encoding region in situ hybridization (EBER-ISH) was positive.

The median viral load at PTLD diagnosis was $4.4 \log$ (3.7-5.1) and the peak EBV PCR during EBV-I was greater than 5 in all cases. Three patients who met the criteria for chronic high EBV load carriers developed PTLD.

All patients with PTLD were treated with anti-CD20 monoclonal antibody (Rituximab) because of progressive disease that did not respond to reduction of IS or because reduction of IS was impossible as occurred in two patients who developed AR with graft failure. Clinical symptoms 


\section{International Journal of Transplantation \& Plastic Surgery}

resolved in all patients and full clearance of EBV replication occurred in three patients during the treatment. No rituximab-related adverse events were observed. Two patients who developed AR after PTLD diagnosis progressed to chronic rejection (CR) at 76 and
107 days after PTLD diagnosis. One of them died due to sepsis after having been treated with sirolimus and low doses of TAC; and the other underwent a re-LT after clinical symptoms resolved (Table 3).

\begin{tabular}{|c|c|c|c|c|c|c|c|}
\hline $\begin{array}{c}\text { Age at } \\
\text { Transplant } \\
\text { (months) }\end{array}$ & $\begin{array}{c}\text { EBV } \\
\text { High } \\
\text { Risk } \dagger\end{array}$ & Previous AR & $\begin{array}{c}\text { Clinical } \\
\text { Presentations }\end{array}$ & $\begin{array}{l}\text { Histological } \\
\text { Classification }\end{array}$ & EBER-ISH & $\begin{array}{l}\text { Chronic } \\
\text { Rejection }\end{array}$ & Evolution \\
\hline 12 & + & Yes & $\begin{array}{c}\text { Lymphadenopathy - } \\
\text { Hepatitis }\end{array}$ & Polymorphic PTLD & + & No & $\begin{array}{l}\text { Resolved - } \\
\text { Alive }\end{array}$ \\
\hline 12 & + & Yes & $\begin{array}{c}\text { Lymphadenopathy - } \\
\text { Enteritis }\end{array}$ & Polymorphic PTLD & + & Yes** & Re LT-Alive \\
\hline 18 & - & Yes & $\begin{array}{c}\text { Lymphadenopathy - } \\
\text { Hepatitis }\end{array}$ & Early lesions * & - & No & $\begin{array}{l}\text { Resolved - } \\
\text { Alive }\end{array}$ \\
\hline 10 & + & No & $\begin{array}{c}\text { Lymphadenopathy - } \\
\text { Hepatitis }\end{array}$ & Early lesions * & + & Yes** & Death (272) \\
\hline
\end{tabular}

† Donor +/Recipient- o R $\leq 12$ months of age

* Late PTLD; developed AR in first week after reduction of immunosuppression

** CR: 76 and 107 days after PTLD diagnosis

Table 3: Details of patients who received treatment.

\section{EVB-I Survival}

Two patients died among the 31 patients who received a first LT and developed EBV-I. Kaplan-Meier estimate of overall patient survival with EBV-I in the first and third year post-LT was 96 and $89 \%$, respectively (Figure 2).

The causes of death were sepsis due to graft failure related to CR treated with sirolimus and low doses of TAC at 6.6 months after PTLD diagnosis and pulmonary thromboembolism at 3.5 months after LT with an unresolved EBV-I.

Three children (3.2\%) experienced graft failure ( 2 died and 1 underwent re-LT due to CR). Kaplan-Meier estimate of graft survival in the first and third year postLT was $96 \%$ and 85\%, respectively (Figure 3). The difference between graft survival in patients who developed PTLD and those who were PTLD free was significant $(66 \%$ at 1 year and $33 \%$ at 3 years vs. $96 \%$; $p=$ 0.008) (Figure 4).

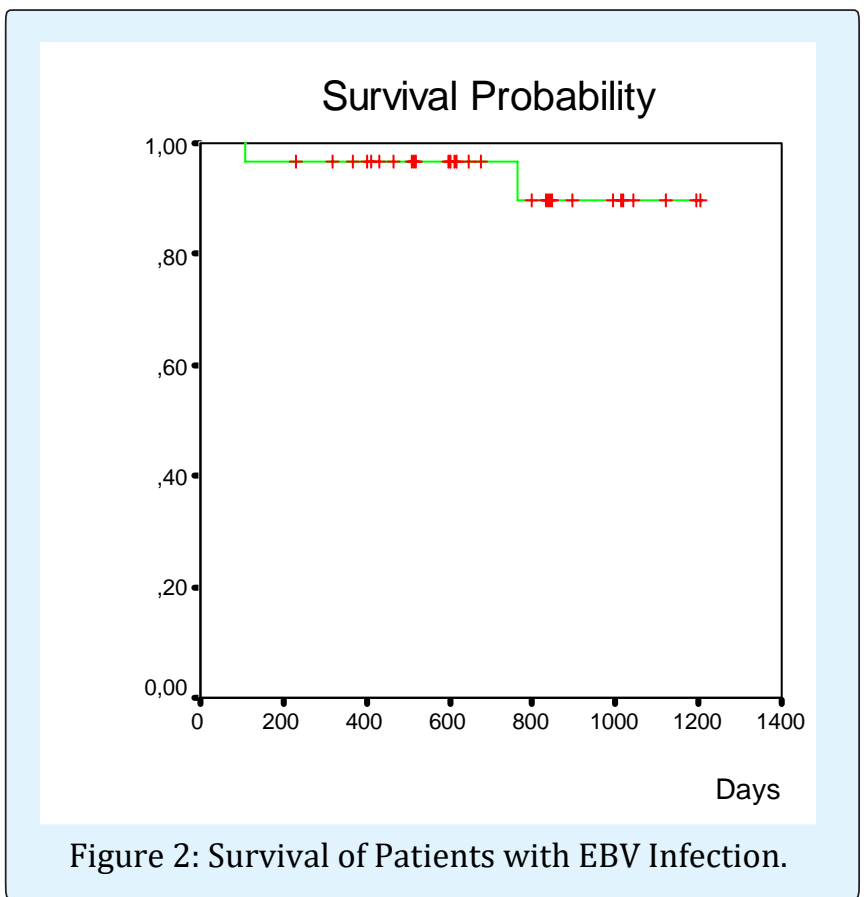

Borgnia D, et al. Management and Incidence of EBV Infection in Children after Liver Transplantation Treated With Tacrolimus. Int J Transplant \& Plastic Surg 2017, 1(1): 000103.

Copyright $(C)$ Borgnia D, et al. 


\section{International Journal of Transplantation \& Plastic Surgery}
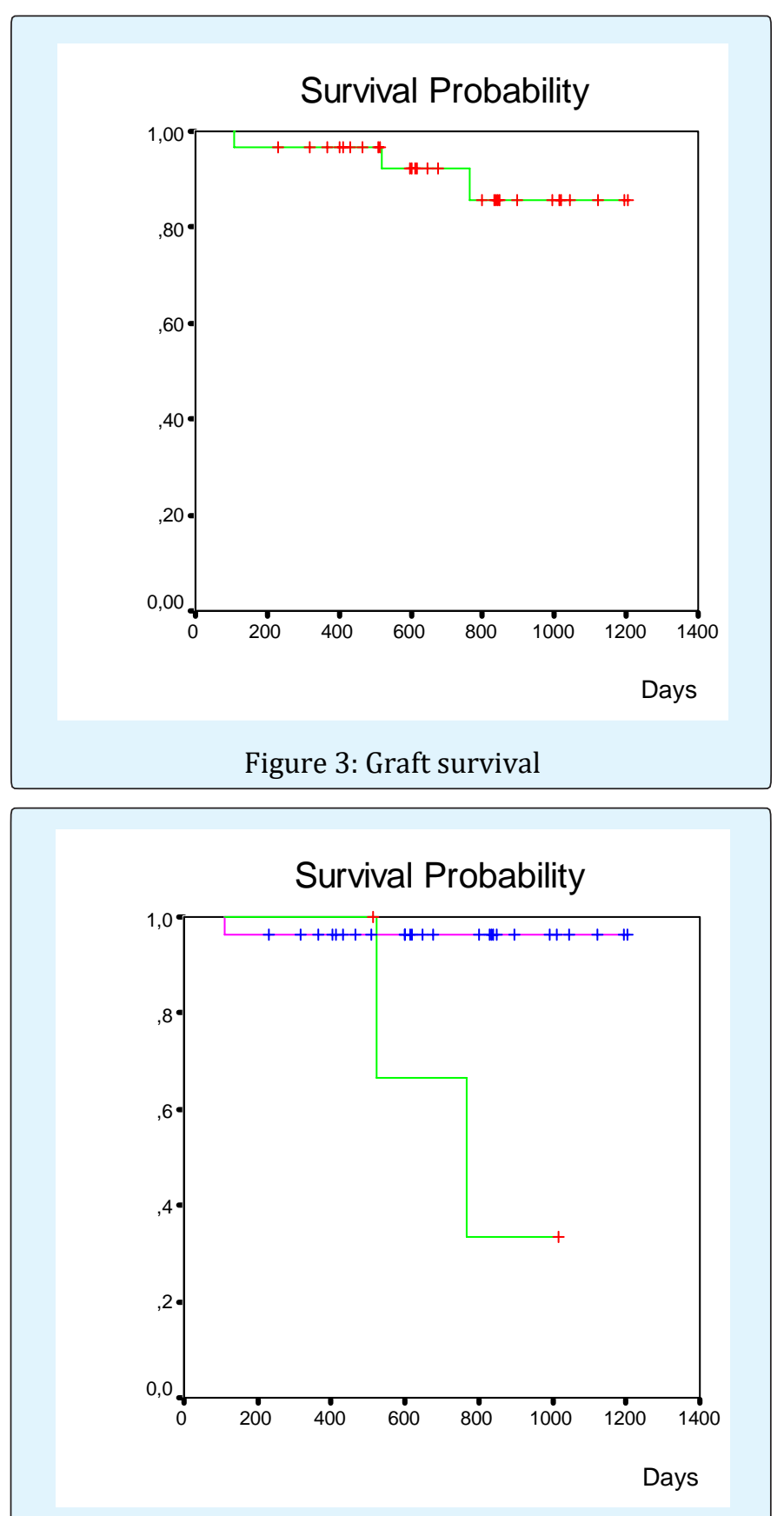

Figure 4: Graft survival in patients who developed PTLD

\section{Discussion}

As we have mentioned, there are several risk factors for the development of PTLD. The limitation of this study is its small sample size with a wide variability in the length of follow-up.
Nevertheless, the prevalence of EBV-I and PTLD in our population was similar to that found in the literature $[5,6]$. As previously described, we found that EBV-I was more frequent in children who were under the age of two years, those who were EBV-naive at the time of transplantation, and those who had more episodes of AR [11].

Overall patient and graft survival in children with EBVI is high but when they develop SEBV or PTLD, graft failure increases significantly.

Currently there is no definitive treatment regimen for this spectrum of diseases; however, reduction of IS is the mainstay therapy for prevention [18-20].

Therefore we treated patients only when a persistently high EBV DNA level was coupled with clinical symptoms and signs of EBV or PTLD in patients who failed to respond to reduction of IS.

In our study we found a high rejection rate compared to data reported by other centers. We observed that the time lapse between transplantation and EBV-I was considerably less in patients with AR than in those without. A similar correlation was found with higher levels of IS in patients with AR shown by TAC blood levels. Within the group of AR patients no significant difference was found between those who developed AR before the EBV-I and those who did after. However, as only four patients with PTLD developed AR, the sample is too small to draw definitive conclusions.

Over the past years there have been many advances in this field. IS regimens have changes and prophylaxis or prevention strategies based on viral load monitoring have been incorporated $[19,20]$. There are no data to support a preference for whole blood, plasma or serum; all are appropriate specimens for monitoring EBV DNAemia $[21,22]$. Given the small size of the sample we could not propose and evaluate a viral load value predictive of PTLD.

We believe it is necessary to continue working to achieve even better results and, similar to other authors, we emphasize the importance of the availability of viral load monitoring which serves as a marker of the degree of IS of the patient allowing for early and adequate intervention if necessary. Therefore we are hopeful a decrease in incidence in SEBV and PTLD may be achieved. 


\section{International Journal of Transplantation \& Plastic Surgery}

Prospective studies are needed to develop prediction models for PTLD risk and improve risk-stratified treatment algorithms for PTLD. Future research should focus on the management of patients with subclinical EBV targeting younger patients, EBV naïve recipients and those who have more rejection episodes who seem to be at the highest risk for SEBV and PTLD.

\section{References}

1. Young LS, Rickinson AB (2004) Epstein-Barr virus: 40 years on. Young L., Rickinson A. Nat New Cancer 4(10): 757-768.

2. Thorley-Lawson DA, Gross A (2004) Persistence of the Epstein - Barr virus and the origins of associated lymphomas. N Engl J Med 350(13): 1328-1337.

3. Gottschalk S, Rooney CM, Heslop HE (2005) Posttransplant lymphoproliferative disorders. Annu Rev Med 56: 29-44.

4. Opelz G, Döhler B (2003) Limphomas after solid organ transplantation: a collaborative transplant study report. Am J Transplant 4(2): 222-230.

5. Cox KL, Lawrence-Miyasaki LS, Garcia-Kennedy R, Lennette ET, Martinez OM, et al. (1995) An increased incidence of Epstein-Barr virus infection and lymphoproliferative disorder in young children on FK506 after liver transplantation. Transplantation 59(4): 524-529.

6. Younes BS, McDiarmid SV, Martin MG, Vargas JH, Goss JA, et al. (2000) The effect of immunosuppression on posttransplant lymphoproliferative disease in pediatric liver transplant patients. Transplantation 70(1): 94-99.

7. Tsao L, Hsi ED (2007) The clinicopathologic spectrum of posttransplantation lymphoproliferative disorders. Arch Pathol Lab Med 131(18): 1209-1218.

8. Al Sinani S, Dhawan A (2009) Corticosteroids usage in pediatric liver transplantation: To be or not to be! Pediatr Transplantation 13(2): 160-170.

9. Ho M, Jaffe R, Miller G, Breinig MK, Dummer JS, et al. (1988) The frequency of Epstein Barr virus infection and associated lymphoproliferative syndrome after transplantation and its manifestations in children. Transplantation 45(4): 719-727.

Borgnia D, et al. Management and Incidence of EBV Infection in Children after Liver Transplantation Treated With Tacrolimus. Int J Transplant \& Plastic Surg 2017, 1(1): 000103.
10. Guthery SL, Heubi JE, Bucuvalas JC, Gross TG, Ryckman FC, et al. (2003) Determination of risk factors for Epstein-Barr virus-associated posttransplant lymphoproliferative disorder in pediatric liver transplant recipients using objective case ascertainment. Transplantation 75(7): 987-993.

11. Narkewicz MR, Green M, Dunn S, Millis M, McDiarmid S, et al. (2013) Decreasing Incidence of Symptomatic Epstein - Barr virus Disease and Posttransplant Lymphoproliferative Disorder in Pediatric Liver Transplant Recipients: Report of the Studies of Pediatric Liver Transplantation Experience. Liver Transpl 19(7): 730-740.

12. Harris NL, Ferry JA, Swerdlow SH (1997) Posttransplant lymphoproliferative disorders: Summary of Society for Hematopathology Workshop.. Semin Diagn Pathol 14(1): 8-14.

13. (1997) Banff Schema for Grading Liver Allograft Rejection: An International Consensus Document. Anonymous. Hepatology 25(3): 658-663.

14. Bingler MA, Feingold B, Miller SA, Quivers E, Michaels MG, et al. (2008) Chronic High Epstein-Barr viral load state and risk for late-onset posttransplant lymphoproliferative disease/lymphoma in children. Am J Transplant 8(2): 442-445.

15. Venuta ME, Rosales E, Viale D, Borgnia D, Irazu L, et al. (2015) Tamizaje de infecciones por virus Epstein Barr en muestras de sangre mediante el uso de una PCR en tiempo real previo a la cuantificación de la carga viral. Medicina Infantil 22(1): 11-15.

16. McDiarmid SV, Jordan S, Kim GS, Toyoda M, Goss JA, Vargas JH, et al. (1998) Prevention and preemptive therapy of postransplant lymphoproliferative disease in pediatric liver recipients. Transplantation 66(12): 1604-1611.

17. Kotton C, Kumar D, Caliendo A, Asberg A, Chou S, et al. (2013) Updated International Consensus Guidelines on the Management of Cytomegalovirus in SolidOrgan Transplantation. Transplantation 96(4): 333360.

18. Kotton CN (2013) CMV: Prevention, Diagnosis and Therapy. Am J Transplant 13(3): 24-40.

19. Gras JM, Gerkens S, Beguin C, Janssen M, Smets F, et al. (2008) Steroid-Free, Tacrolimus-Basiliximab 


\section{International Journal of Transplantation \& Plastic Surgery}

Immunosuppression in Pediatric Liver Transplantation: Clinical and Pharmacoeconomic Study in 50 Children. Liver Transpl 14(4): 469-477.

20. Lee TC, Savoldo B, Rooney CM, Heslop HE, Gee AP, et al. (2005) Quantitative EBV viral loads and immunosuppression alterations can decrease PTLD incidence in pediatric liver transplant recipients. Am J Transplant 5(9): 2222-2228.
21. Holmes RD, Orban-Eller $\mathrm{K}$, Karrer FR, Rowe DT, Narkewicz MR, et al. (2002) Response of elevated Epstein-Barr virus DNA levels to therapeutic changes in pediatric liver transplant patients: 56-month follow up and outcome. Transplantation 74(3): 367372 .

22. Fishman JA (2017) Infection in Organ Trasplantation. Am J Transplant 17(4): 856-879. 